Article

\title{
International Comparison of Total Factor Ecology Efficiency: Focused on G20 from 1999-2013
}

\author{
Shujing Yue *, Yang Yang, Jun Shao and Yuting Zhu \\ School of Economics \& Management, Southeast University, Nanjing 211189, China; 220151825@seu.edu.cn (Y.Y.); \\ 101010961@seu.edu.cn (J.S.); 220161860@seu.edu.cn (Y.Z.) \\ * Correspondence: yueshujing@seu.edu.cn; Tel.: +86-25-5209-0700; Fax: +86-25-5209-0702 \\ Academic Editors: Yongrok Choi, Malin Song and Seunghwan Myeong \\ Received: 8 August 2016; Accepted: 31 October 2016; Published: 3 November 2016
}

\begin{abstract}
Little attention has been paid to international ecological efficiency, especially taking ecological footprint (EF), labor, and capital into account as multi-inputs to produce GDP in the total-factor framework. This study evaluates the total-factor ecological efficiency (TFEcE) of G20 during the period of 1999-2013 by employing slack-based measure (SBM) with EF as the index of comprehensive ecological inputs. Findings show that the average level of TFEcE of G20 from 1999 to 2013 is at a low level of about 0.54, which means there is a large space for the improvement of TFEcE. Furthermore, TFEcE of G20 is very imbalanced and there is a big gap between developed countries and developing countries in the G20. For the developing countries and developed countries in the G20, the analysis of factors that affect national TFEcE shows different statistical significance in the truncated regression model.
\end{abstract}

Keywords: slack-based measure (SBM); ecological footprint (EF); total-factor ecological efficiency (TFEcE)

\section{Introduction}

Efficient ecology consumption is a top priority in the ecological field in terms of both resource conservation and control of climate change. Over the last few decades, the world has witnessed large ecological degradation problems, including increasing greenhouse gas emission, high energy consumption, deforestation, land erosion, and groundwater exhaustion. Thus, it is necessary to take both economic and ecological factors into account in policy-making. In general, accepting declining economic growth as a consequence of decreased ecological consumption is not practicable. Improving ecological efficiency, not only maximizing economic objectives but also minimizing ecological concerns, is important for every economy.

Ecological efficiency is concerned with creating more value with less impact [1]. In empirical studies, ecological efficiency has always been measured in the presence of the ratio of macroeconomic variables (especially GDP (gross domestic product)) to ecological inputs. Despite the wide-ranging literature that has investigated the relationship between GDP and ecological inputs, most of the studies have focused on utilizing $\mathrm{CO}_{2}$ emissions or energy consumption as an indicator of ecological inputs which just represents a portion of them. Thus, to have a better understanding of ecological efficiency, this study will utilize the ecological footprint (EF) as a comprehensive indicator of ecological inputs.

Ecology input alone cannot produce any output. Ecology must be put together with other inputs, such as labor and capital, to produce GDP. Consistent with the view that single-factor energy efficiency index has some disadvantages in empirical studies [2], likewise, single-factor ecological efficiency index (ecological inputs to GDP ratio) in the previous literature would also lead to misleading conclusions. Therefore, a multi-input model considering other inputs in a total-factor framework should be applied to correctly assess the ecological efficiency. 
Different from the papers such as $\mathrm{Hu}$ and Wang [3] who only took energy into account as ecological inputs in a total-factor framework, and different from the existing papers using EF to evaluate single-factor ecology efficiency, this paper considers EF, labor, and capital as multi-inputs to assess the ecological efficiency in a total-factor framework, and we have named this index total-factor ecological efficiency (TFEcE).

The purpose of this study is to evaluate the TFEcE of the G20 during the period of 1999-2013 by employing slacks-based measure (SBM). To our knowledge, little attention has been paid to international ecological efficiency, especially taking ecological footprint (EF), labor, and capital into account as multi-inputs to produce GDP in the total-factor framework. This paper is organized as follows. Section 2 reviews the previous studies. Section 3 gives the methodology and describes the data we use for our analysis. Section 4 presents the empirical results and discussions. Finally, Section 5 concludes this paper.

\section{Literature Overview}

Different from the previous research which studies the EF and total-factor framework separately, this paper combines the concept of EF with the framework of total-factor. Our study is particularly related to two strands of literature.

The first strand focuses on ecological efficiency. Ecological-efficiency is concerned with creating more value with less impact [1]. The concept of ecological efficiency was originated from environmental efficiency [4], then in 1989 Schaltegger and Sturm (1989) [5] first described it as a "business like to sustainable development". Later, ecological efficiency was popularized by the establishment of the World Business Council for Sustainable Development (WBCSD) [6].

Although ecological efficiency assessment is a complicated and multidisciplinary task [7], it is widely measured as the ratio between the added value of a product or service and the ecological impacts of the product or service. In empirical study, GDP is often used as the numerator, and consumption of energy [3], emissions of $\mathrm{CO}_{2}$ [8], domestic extraction [9] or material flow [10] is usually placed in the denominator as indicators of ecological pressure.

The most comprehensive measure of humanity's overall impact may be EF, which was first proposed by Rees [11] and elaborated by Wackernagel and Rees [12]. Since then, EF is widely applied to assess sustainability. Moffatt [13] suggested that by combining EF with more methods, further detailed work of relevance to policy makers would become available. Kratena [14] described the concept of ecosystem pricing in an input-output system based on the concept of the EF. Chen et al. [15] stated that the ratio of GDP to EF can be considered as a measure of the resource efficiency. Fu et al. [16] calculated the resource productivity (RP) by using the EF as an indicator of the natural resource input and GDP as the output in the equation of RP = GDP/EF. By using the data of EF, Miao et al. [17] measured ecological carrying capacity, ecological deficit, and surplus in Anhui province in China.

The second strand of research related to this paper is concerned with total-factor framework, especially with total-factor energy efficiency. Hu and Wang [3] argued that energy alone cannot produce any output and energy needs to be put together with labor and capital in order to produce outputs. Therefore, a multiple model should be applied to correctly evaluate the energy efficiency. Under the total-factor framework, $\mathrm{Hu}$ and Wang [3] first proposed the total-factor energy efficiency (TFEE) index and employed it to analyze energy efficiencies of 29 administrative regions in China. By incorporating water as an input as well as using conventional inputs such as capital stock and labor employment, $\mathrm{Hu}$ et al. [18] calculated the total-factor water efficiency and found that there was a U-shape relation between the total-factor water efficiency and per capita real income among areas in China. Furthermore, Hu and Kao [19] studied energy-saving target ratios for 17 APEC economies and discovered an increasing trend except for Canada and New Zealand. Honma and Hu [20] employed the data envelopment analysis (DEA) to calculate the regional TFEE in Japan, and 14 inputs (3 production factors, 11 energy sources) are included in this model. Zhang et al. [21] used a total-factor framework to investigate energy efficiency in 23 developing countries during the period of 1980-2005, and found 
that China experienced the most rapid rise in TFEE. Chang and $\mathrm{Hu}$ [22] introduced the total-factor energy productivity index (TFEPI) based on the concept of TFEE and the Luenberger productivity index to evaluate the energy productivity change of regions in China. $\mathrm{Li}$ and $\mathrm{Hu}$ [23] computed the ecological total-factor energy efficiency (ETFEE) of 30 provinces in China for the period 2005-2009 through the SBM with undesirable outputs. Zhang et al. [24] proposed a metafrontier slack-based efficiency measure approach to assess ETFEE and empirically analyzed regional ETFEE of China during 2001-2010.

The first strand of literature related to ecological efficiency only regarded ecological input as a single input to produce GDP, while neglecting other key inputs such as capital and labor; the second strand of literature related to the total-factor energy efficiency only considered energy as ecological input, while ignoring other ecological inputs such as water, forest, and land. Therefore, this paper attempts to use EF as the index of comprehensive ecological inputs, as well as taking labor and capital into account, to assess the ecological efficiency of G20 in a total-factor framework.

\section{Methodology and Data Source}

In this section, we first calculate EF which is the aggregate area of land and water in six ecological categories, then consider $\mathrm{EF}$ as the comprehensive measurement of ecological inputs and introduce it into the SBM model which takes capital and labor into account, to assess the TFEcE of G20 in a total-factor framework.

\subsection{Ecological Footprint}

EF is a simple assessment method for sustainable development from the perspective of the aggregate area of productive lands and water required to produce all the resources consumed and to assimilate all the wastes produced [25]. EF transfers the consumption of different ecological resources into various productive lands, and the lands can be divided into six types: arable land, pasture land, forest land, fisheries land, fossil energy land, and built-up land.

The calculation method of EF from 1999-2013 for G20 is mainly based on the compound approach proposed by Wackernagel et al. [26]. The computational formula for EF is as follows:

$$
\mathrm{EF}=\sum \frac{P_{i}}{Y_{P i}} \times Y F_{i} \times E Q F_{i}
$$

In the above Equation (1), EF represents the total ecological footprint; $i$ is the type of resource consumed by a certain amount of population; $P_{i}$ is the quantity of the $i$ th resource consumed; $Y_{P i}$ is the average productivity for producing $i$ th type of resource; $Y F_{i}$ is the yield factor of $i$ th land type, which describes the extent to which a biologically productive area in a given country is more (or less) productive than the global average of the same bioproductive area; $E Q F_{i}$ is the equivalence factor of $i$ th land type, which represents the world average productivity of given productive land relative to the global average productivity of all productive lands.

The consumption of biological resources (including arable land, pasture land, forest land, and fisheries land) cannot be calculated directly, so the trade adjustment is conducted. The steps are as follows. First, calculate the biological resources manufacturing footprint based on national statistics of biological production. Second, calculate the biological resources net export trade footprint based on national trade data of biological resources. Third, deduct net export trade footprint from manufacturing footprint.

\subsection{Slacks-Based Measure (SBM) Model}

Data Envelopment Analysis (DEA) is a non-parametric statistical method based on linear programming technique to assess the efficiencies of decision-making units (DMU) that refer to a set of firms or a set of countries in empirical studies. Built upon the basic DEA models of Charnes et al. [27] and Banker et al. [28], Tone [29] proposed the SBM to measure efficiency based on input excesses 
and output shortfalls. Being a non-radial approach, SBM overcomes the conventional radial DEA method's overestimating-limitation which is caused by neglecting slack variables [30]. Furthermore, SBM directly accounts for input and output slacks in efficiency measurements, with the advantage of capturing the whole aspect of inefficiency [24].

Assume that there are $i=1, \ldots, N$ countries, and each country is a DMU using input vector $x \in \mathrm{R}_{+}^{m}$ to produce output vector $y \in \mathrm{R}_{+}^{\mathrm{n}}$. In this paper, the output vector is national GDP. The input vector contains EF, capital stock, and labor employment. The fractional programming problem of SBM model is expressed as follows:

Minimize

$$
\rho=\frac{1-(1 / m) \sum_{i=1}^{m} s_{i}^{-} / x_{i o}}{1+(1 / n) \sum_{r=1}^{n} s_{r}^{+} / y_{r o}}
$$

Subject to

$$
\begin{aligned}
& x_{o}=X \lambda+S^{-} \\
& \mathrm{y}_{o}=Y \lambda-S^{+}, \lambda \geq 0, \\
& s^{-} \geq 0, \quad s^{+} \geq 0 .
\end{aligned}
$$

where each country has $m$ inputs and $n$ outputs; $\mathrm{s}_{i}^{-}, \mathrm{s}_{r}^{+}, x_{0}$, and $y_{0}$ represent the input slack, the output slack, the inputs, and the outputs for the oth country respectively; $S^{-}, S^{+}, X$, and $Y$ are the corresponding matrices of the input slack, the output slack, the inputs, and the outputs; $\lambda$ is a nonnegative multiplier vector. $\rho$ is the overall efficiency score for the oth country. If $\rho=1$ (which indicates that all the slack variables are 0 ), the oth country is SBM-efficient.

\subsection{Total-Factor Ecology Efficiency (TFEcE)}

TFEE in $\mathrm{Hu}$ and Wang [3], $\mathrm{Li}$ and $\mathrm{Hu}$ [23] is defined as:

$$
\text { TFEE }(o, t)=\frac{\text { Target energy input }(o, t)}{\text { Actual energy input }(o, t)}
$$

where $\operatorname{TFEE}(o, t)$ is the total-factor energy efficiency for region $o$ at time $t$. In Hu and Wang [3], Li and $\mathrm{Hu}$ [23], the target energy input for each region is defined as:

Target energy input $(o, t)=$ Actual energy input $(o, t)-$ Total energy input slack $(o, t)$

Total energy input slacks, which can be obtained from SBM in Hu and Wang [3] and Li and $\mathrm{Hu}$ [23], represent the gap between the target level and actual level. Total energy input slack can be regarded as the inefficient portion of actual energy consumption.

Following the TFEE proposed by $\mathrm{Hu}$ and Wang [3] and $\mathrm{Li}$ and $\mathrm{Hu}$ [23], this paper uses EF instead of energy as the ecological inputs to build the index of TFEcE for country $o$ at time $t$.

According to Formula (3), the input slacks are the total amount that can be reduced without decreasing the output levels. With respect to ecological inputs, the above slacks are called the "ecology input slacks" and the amount of slacks in ecological input is regarded as the inefficiency portion of actual ecological consumption. Based on the slacks of ecology input obtained from Formula (3), considering labor, capital, and EF simultaneously, we can work out the ecology-saving target ratio (ESTR). The formula is as below:

$$
\operatorname{ESTR}(o, t)=\frac{\text { Ecology input slack }(o, t)}{\text { Actual ecology input }(o, t)}
$$

where ESTR represents each country's inefficient level of ecology consumption. ESTR $(o, t)$ refers to the ESTR in the oth country and the th year. TFEcE in this paper has the following relation with ESTR:

$$
\operatorname{TFEcE}(o, t)=1-\operatorname{ESTR}(o, t)
$$


where TFEcE $(o, t)$ refers to the TFEcE in the oth country and the th year. A zero ESTR value implies a country on the frontier with the best TFEcE up to one among the observed countries, while a country with the value of ESTR larger than zero indicates that ecology should and could be saved at the same output level. Therefore, TFEcE lies always between zero and unity and a higher TFEcE implies higher ecological efficiency in a total-factor framework.

\subsection{Data and Material}

The G20 member countries are chosen as the research object because they have worldwide representatives including both developed and less-developed countries. Furthermore, the GDP of G20 accounts for about $90 \%$ of the world GDP and their population accounts for about two-thirds of the world population. G20 consists of the following economies: Argentina, Australia, Brazil, Canada, France, Germany, India, Indonesia, Italy, Japan, Republic of Korea, Mexico, Russian Federation, Saudi Arabia, South Africa, Turkey, UK, USA, and China. The EU is excluded due to the incompleteness of data. The data used in this paper comes from that of 19 countries in the G20 from 1999-2013.

EF refers to various types of resources meeting the daily consumption of a certain human population. In this paper, arable products include cereals, pulses, oil crops, eggs, and vegetables. Forest products include fruit and wood. Pasture products include cattle, mutton, pig, and milk. Fisheries products include fish. Fossil energy land is related to oil, natural gas, and coal. In addition, the consumption of hydro-electricity is converted into that of built-up land.

The above data of the agricultural products (including arable products and pasture products), forest products, and fisheries products are mainly from the FAO STAT, provided by Food and Agriculture Organization of the United Nations. The consumption quantities of oil, natural gas, coal, and hydro-electric can be obtained from BP's statistical review of world energy. We adopt the value of the equivalence factors proposed by Wackernagel and Rees [12].

In SBM model, EF, capital stock and labor are employed as inputs, and GDP as output. EF is calculated by the above method. Capital stock from 1993 to 2013 with 2005 prices is calculated using the Perpetual Inventory Method as the following equation shows:

$$
K_{t}=I_{t}+K_{t-1}(1-\delta)
$$

where $I_{t}$ is the capital formation in the year $t$, which can be obtained from Penn World Table 7.1. $\delta$ is depreciation rate and is set to be $6 \%$ according to the relevant literature [31]. $K_{t}$ is the capital stock in the year $t$. Initial capital stock is estimated by the equation proposed by Nehru and Dhareshwar [32]:

$$
N K_{i}=I_{i} /(\delta+g)
$$

where $N K_{i}$ is the initial capital stock of the research period, $I_{i}$ is the initial capital formation. $g$ is the average capital growth rate during the research period. $\delta$ is depreciation rate.

Data on labor and GDP are collected from the World Development Indicators of the World Bank, and GDP is transformed into constant 2005 U.S. dollars by GDP deflators.

\section{Empirical Analysis}

\subsection{Evaluation of EF in G20 from 1999 to 2013}

As shown in Figure 1, the total EF of G20 maintains a stable growth trend from 1999 to 2013, increasing from 9.62 billion ha in 1999 to 12.03 billion ha in 2013, and achieving a growth of about $25 \%$.

The six different land types of EF are also shown in Figure 1. Fossil energy land contributed most to the total EF among the six components, accounting for $33.77 \%$, and followed by forest and pasture land, whose contributions were $25.38 \%$ and $23.42 \%$ respectively. Arable land ranked fourth with the percentage of $16.9 \%$. The contributions of fisheries and built-up land to total EF were relatively small, and the average proportions were $0.03 \%$ and $0.52 \%$, respectively. 


\section{Ecological Footprint / 10 million ha}

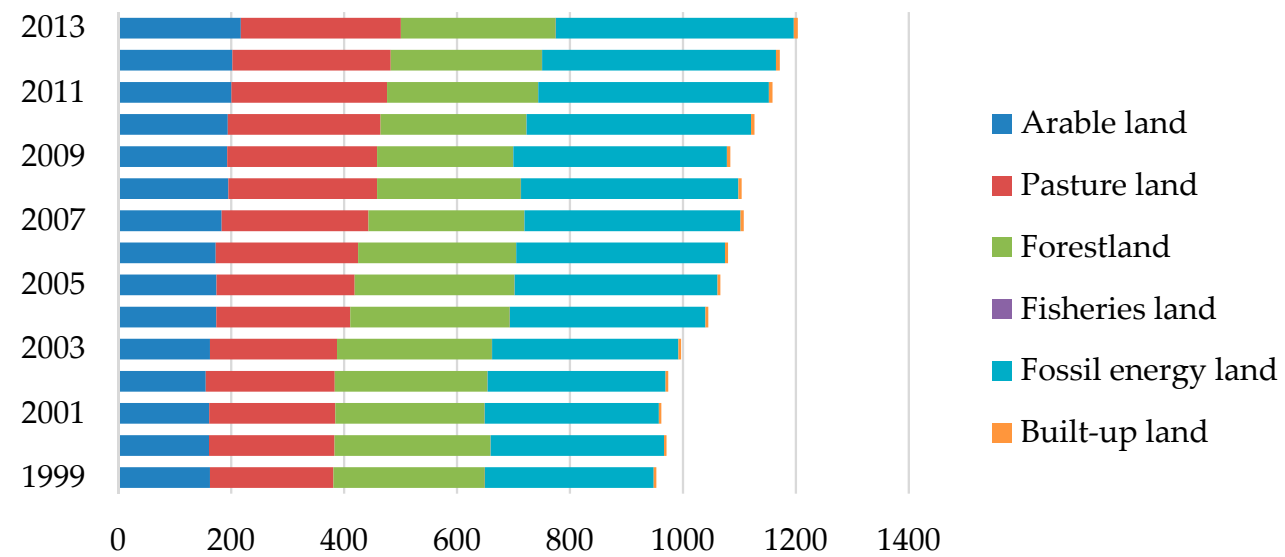

Figure 1. Time series of total EF components in G20 countries 1999-2013.

Over the study period, the proportions of six land types have changed considerably. The EF of fisheries land was the fastest growing component during 1999-2013, and it increased by $67.75 \%$ from 2.6 million ha in 1993 to 4.4 million ha in 2013. The EF of forest land obtained the lowest growth rate of only $2 \%$. The growth rates of pasture, arable, fossil energy, and built-up land were $29.62 \%, 33.69 \%$, $40.97 \%$, and $53.57 \%$ respectively.

The national level of EF is shown in Table 1. Due to the limited space, only data in some specific years are listed. According to the results in Table 1, the EF of G20 countries displays two evolving trends during the research period. Firstly, the EF of seven countries (Australia, Canada, France, Italy, Japan, UK, and USA) declined over time, with the biggest fall taking place in Italy. Secondly, the remaining 12 countries presented an upward trend in EF, with China increasing the most.

Table 1. EF by countries from 1999 to 2013 (10 million ha).

\begin{tabular}{ccccccccc}
\hline Country & $\mathbf{1 9 9 9}$ & $\mathbf{2 0 0 1}$ & $\mathbf{2 0 0 3}$ & $\mathbf{2 0 0 5}$ & $\mathbf{2 0 0 7}$ & $\mathbf{2 0 0 9}$ & $\mathbf{2 0 1 1}$ & $\mathbf{2 0 1 3}$ \\
\hline Argentina & 14.300 & 12.697 & 13.011 & 14.628 & 15.451 & 15.806 & 15.668 & 17.982 \\
Australia & 18.171 & 19.589 & 20.588 & 20.148 & 19.967 & 19.079 & 19.038 & 18.047 \\
Brazil & 56.337 & 56.131 & 63.123 & 62.603 & 65.376 & 64.610 & 70.363 & 72.958 \\
Canada & 52.264 & 50.286 & 50.966 & 55.581 & 47.944 & 38.424 & 44.034 & 45.613 \\
France & 32.510 & 32.970 & 31.140 & 31.796 & 31.779 & 30.973 & 30.466 & 29.471 \\
Germany & 39.436 & 39.998 & 41.125 & 42.017 & 44.893 & 40.650 & 42.199 & 43.103 \\
India & 105.680 & 109.126 & 113.883 & 121.451 & 131.497 & 137.890 & 148.858 & 153.258 \\
Indonesia & 28.795 & 26.894 & 29.429 & 28.806 & 29.879 & 31.059 & 34.722 & 35.370 \\
Italy & 22.529 & 21.891 & 22.016 & 22.485 & 21.955 & 20.385 & 20.495 & 18.806 \\
Japan & 36.860 & 35.777 & 36.273 & 36.309 & 35.873 & 32.181 & 33.826 & 35.254 \\
Republic of Korea & 12.980 & 13.604 & 14.287 & 14.384 & 15.003 & 15.064 & 16.264 & 16.908 \\
Mexico & 22.168 & 23.402 & 23.925 & 24.882 & 26.087 & 25.356 & 26.274 & 26.512 \\
Russian & 66.106 & 75.103 & 74.506 & 74.765 & 80.060 & 75.070 & 81.699 & 80.829 \\
Saudi Arabia & 7.237 & 7.731 & 8.707 & 9.747 & 10.553 & 11.609 & 13.195 & 14.351 \\
South Africa & 11.473 & 11.599 & 12.446 & 13.077 & 13.141 & 13.682 & 13.398 & 13.321 \\
Turkey & 14.643 & 14.168 & 15.593 & 16.530 & 18.293 & 18.366 & 21.336 & 23.095 \\
UK & 22.343 & 22.470 & 22.628 & 22.537 & 22.338 & 21.039 & 20.612 & 20.949 \\
USA & 244.785 & 240.907 & 245.511 & 255.476 & 252.503 & 226.666 & 234.256 & 239.207 \\
China & 153.842 & 156.807 & 167.147 & 209.142 & 234.635 & 254.332 & 281.315 & 298.441 \\
\hline
\end{tabular}

China and USA were the two countries with the highest EF. China's EF, with the total growth of $94 \%$ from 1999 to 2013, exceeded that of the USA in 2008 and the gap of EF between China and USA extended to 59.2510 million ha in 2013. India's EF ranked the third and increased by nearly half from 105.6810 million ha in 1999 to 153.2610 million ha in 2013. Compared with these three countries, the EF of the remaining countries were at lower levels. Among all the countries, the EF of Saudi Arabia was the smallest, but its growth rate was the highest, which was $98.31 \%$, from 7.2410 million ha in 1993 to 14.3510 million ha in 2013. 


\subsection{Analysis of the G20's TFEcE}

According to the Formulas (6) and (7) in Section 3, we calculate the TFEcE of G20, and the results are shown in Table 2. In general, the average TFEcE of G20 from 1999 to 2013 is at a low level of about 0.54 , which urgently needs to be improved. The actual ecological inputs could be reduced by almost $46 \%$, with output unchanged, through ecological efficiency improvement. This indicates that the improvement of ecological efficiency is an effective way to maintain economic growth, and meanwhile, to relieve ecological pressure.

Table 2. Total-factor ecology efficiency (TFEcE) by countries (1999-2013).

\begin{tabular}{ccccccccc}
\hline Country & $\mathbf{1 9 9 9}$ & $\mathbf{2 0 0 1}$ & $\mathbf{2 0 0 3}$ & $\mathbf{2 0 0 5}$ & $\mathbf{2 0 0 7}$ & $\mathbf{2 0 0 9}$ & $\mathbf{2 0 1 1}$ & $\mathbf{2 0 1 3}$ \\
\hline Argentina & 0.267 & 0.290 & 0.270 & 0.182 & 0.167 & 0.150 & 0.191 & 0.154 \\
Australia & 0.384 & 0.373 & 0.356 & 0.379 & 0.389 & 0.378 & 0.376 & 0.408 \\
Brazil & 0.333 & 0.334 & 0.288 & 0.323 & 0.312 & 0.208 & 0.283 & 0.260 \\
Canada & 0.220 & 0.269 & 0.354 & 0.208 & 0.225 & 0.408 & 0.307 & 0.251 \\
France & 0.930 & 0.933 & 0.672 & 0.657 & 0.642 & 0.630 & 0.647 & 0.648 \\
Germany & 0.758 & 0.743 & 0.688 & 0.652 & 0.615 & 0.641 & 0.620 & 0.598 \\
India & 0.245 & 0.250 & 0.299 & 0.392 & 0.264 & 0.265 & 0.177 & 0.203 \\
Indonesia & 0.356 & 0.414 & 0.417 & 0.507 & 0.363 & 0.365 & 0.357 & 0.359 \\
Italy & 1.000 & 1.000 & 0.811 & 0.770 & 0.766 & 0.770 & 0.741 & 0.830 \\
Japan & 1.000 & 1.000 & 1.000 & 1.000 & 1.000 & 1.000 & 1.000 & 1.000 \\
Republic of Korea & 0.702 & 0.675 & 0.711 & 0.693 & 0.669 & 0.668 & 0.594 & 0.593 \\
Mexico & 0.557 & 0.569 & 0.574 & 0.425 & 0.508 & 0.580 & 0.568 & 0.614 \\
Russian & 0.467 & 0.629 & 0.436 & 0.394 & 0.230 & 0.121 & 0.238 & 0.239 \\
Saudi Arabia & 0.648 & 0.673 & 0.568 & 0.568 & 0.593 & 0.640 & 0.545 & 0.514 \\
South Africa & 0.462 & 0.582 & 0.574 & 0.533 & 0.404 & 0.203 & 0.204 & 0.208 \\
Turkey & 0.649 & 0.585 & 0.612 & 0.552 & 0.275 & 0.248 & 0.254 & 0.242 \\
UK & 1.000 & 1.000 & 1.000 & 1.000 & 1.000 & 1.000 & 1.000 & 1.000 \\
USA & 1.000 & 1.000 & 1.000 & 1.000 & 1.000 & 1.000 & 1.000 & 1.000 \\
China & 0.238 & 0.253 & 0.238 & 0.271 & 0.281 & 0.330 & 0.268 & 0.285 \\
Developed countries & 0.764 & 0.767 & 0.716 & 0.692 & 0.690 & 0.714 & 0.683 & 0.684 \\
Developing countries & 0.397 & 0.434 & 0.412 & 0.398 & 0.312 & 0.274 & 0.282 & 0.285 \\
\hline & & & & & & &
\end{tabular}

According to the human development index of United Nations Development Program (UNDP) and the classification of countries proposed by the World Bank, the developed countries mentioned in this study include Australia, Canada, France, Germany, Italy, Japan, Republic of Korea, Saudi Arabia, USA, and UK, and the rest belong to the developing countries.

As Table 2 presents, TFEcE of the G20 is very imbalanced. There is a big gap between developed countries and developing countries. For the average value, TFEcE of developed countries reached 0.714 , double what it is in developing countries, 0.352 . For the median value, TFEcE of developed countries reached 0.705 , which is 1.97 times that of developing countries, 0.358 . For the degree of divergence, the standard deviation of TFEcE in developed countries is 0.031 , just a half of that in developing countries, 0.062 . According to the gap between developed countries and developing countries in the G20 in terms of their TFEcE, it showed an upward trend with fluctuation, rising from 0.367 in 1999 to 0.399 in 2013. In 2009, the gap reached a maximum, which is 0.439 .

In order to further confirm the gap between developed countries and developing countries, Mann-Whitney U rank test is applied to carry out a significance test. We can see from Table 3, there exists a significant difference between the TFEcE of developed countries and that of developing countries.

Table 3. Significance test of TFEcE between developed and developing countries.

\begin{tabular}{ccccc}
\hline Countries & Mann-Whitney U & Wilcoxon $\mathbf{W}$ & Z-Value & $p$-Value \\
\hline Developed vs. Developing & 0.000 & 120.000 & -4.666 & $<0.001$
\end{tabular}

Notes: Mann-Whitney $U$ test is a nonparametric test of the null hypothesis that the distribution of the two populations which the two independent samples come from has no significant difference.

In terms of specific countries, three countries-USA, UK, and Japan-found the optimal efficiency during the research period, and they are all developed countries. These three countries are followed 
by Italy, France, Republic of Korea, and Germany at $0.84,0.71,0.67$, and 0.66 , respectively. The TFEcE of Saudi Arabia, Mexico, and Turkey are around the average level of all the countries. South Africa, Indonesia, and Australia gain almost the same TFEcE, fluctuating around 0.39. The country with the lowest TFEcE score is Argentina, and the average score is 0.21 during 1999-2013.

It is worth noting that among those developed countries, TFEcEs of Canada and Australia, respectively 0.386 and 0.275 , are relatively lower than other developed countries. TFEcE assessment involves input variables (EF, labor, and capital), as well as an output variable (GDP). The main reason of the lower TFEcEs of the two countries is that their EF inputs are relatively high. Statistics data can be used to illustrate. Compared with France, labor, capital, and GDP values of Australia were 37.5\%, $41.7 \%$, and $32.5 \%$, respectively, while the EF value that Australian occupied is just $60.1 \%$ of that of France. Compared with France, labor, capital, and GDP values of Canada were respectively $62.2 \%$, $52.3 \%$, and $52.9 \%$, but the EF value that Canada occupied is $153.7 \%$ of that of France. EF consists of six different ecological land types. Different resource endowments of Australia and Canada lead to different occupation of ecological land types. The pasture land footprint in Australia (which accounts for $40.5 \%$ of the country's total EF) and the forestland footprint in Canada (which accounts for $57.7 \%$ of the country's total EF) are relatively higher, and which lead to the higher total EF and also the lower TFEcEs of them.

Russia, Brazil, and China, the three most populous developing countries, have relatively low TFEcE scores. Though China's TFEcE is small, its growth rate is the highest at $19.7 \%$ from 0.238 in 1999 to 0.285 in 2013. The TFEcE of China in 1993 was only 0.238, which was lower than that of Argentina, while in 2013 the TFEcE of China was 1.85 times as high as that of Argentina. China's TFEcE ranked 18th in 1999 and 12th in 2013, which may benefit from the relevant effective measures taken by Chinese government, including the "National Program on Climate Change" first proposed by developing countries in 2006 and the "Energy Conservation Binding Targets" established in 2009.

\subsection{Comparison of G20 Countries' TFEcE and TFEE}

The essential difference between TFEE proposed by Hu and Wang [3] and TFEcE in this paper is whether to incorporate the comprehensive ecological impacts. TFEcE takes not only the energy inputs, but also the water, forest, and arable inputs into account, which evaluates ecology efficiency more comprehensively. Tables 2 and 4 respectively show the TFEcE and TFEE of G20, and Table 4 also presents the difference between TFEcE and TFEE of G20.

Without considering other ecological impacts, TFEE may overestimate the country's performance. As Table 4 shows, during 1999-2013, the average of TFEE of G20 is 0.617, while the average of TFEcE is 0.543. The Mann-Whitney U rank test proves that the difference between TFEE and TFEcE presents a statistical significance with a $p$-value less than 0.001 as Table 5 shows. The comparative result means that consideration of EF as comprehensive ecological inputs has a significant influence on the country's ecology efficiency.

At the national level, Table 4 shows the gap between TFEE and TFEcE of G20. The countries can be divided into three groups. The first group includes UK and USA. There is no difference between TFEE and TFEcE for these two countries, because they always stand on the efficient frontier and rank first for both TFEE and TFEcE for each year. The second group includes Japan, Republic of Korea, Saudi Arabia, and South Africa. The TFEE of these countries are lower than their TFEcE. In this group, Saudi Arabia presents the biggest difference between TFEE and TFEcE, which are 0.35 and 0.6 respectively. The main reason may be that Saudi Arabia is an "oil kingdom", one of the countries that has the largest oil reserves and production. The process of production, exploration, and exploitation of petroleum need to consume much energy, and the relative low price of oil also induces more energy consumption. These factors lead to low TFEE score in Saudi Arabia. However, Saudi Arabia's TFEcE is higher than its TFEE, which indicates that Saudi Arabia has made efforts to improve efficiency of other ecological inputs. The efforts on other ecological impacts made by these countries in the second group would be ignored if we only considered the energy input as the whole ecological inputs. The rest of the countries 
belong to the third group, whose TFEE is higher than their TFEcE. These countries have paid more attention to energy consumption, with less attention to biological EF (including arable lands, pasture lands, forest lands, and fisheries lands). Taking China as an example, the average of TFEE is 0.31, while the TFEcE score is 0.28 . This indicates that China has achieved much more progress in energy saving, with less progress in other ecological inputs reduction. For the countries in the last group, they should vigorously promote energy savings and other biological EF reduction at the same time.

Table 4. TFEE, difference between TFEcE and TFEE by countries (1999-2013).

\begin{tabular}{ccccccccccc}
\hline Country & \multicolumn{3}{c}{ Total-Factor Energy Efficiency } & \multicolumn{5}{c}{ Difference between TFEcE and TFEE } \\
\hline & $\mathbf{1 9 9 9}$ & $\mathbf{2 0 0 1}$ & $\mathbf{2 0 0 5}$ & $\mathbf{2 0 0 9}$ & $\mathbf{2 0 1 3}$ & $\mathbf{1 9 9 9}$ & $\mathbf{2 0 0 1}$ & $\mathbf{2 0 0 5}$ & $\mathbf{2 0 0 9}$ & $\mathbf{2 0 1 3}$ \\
\hline Argentina & 0.558 & 0.563 & 0.409 & 0.312 & 0.295 & 0.291 & 0.273 & 0.228 & 0.162 & 0.141 \\
Australia & 0.604 & 0.604 & 0.588 & 0.521 & 0.524 & 0.219 & 0.231 & 0.210 & 0.143 & 0.116 \\
Brazil & 0.527 & 0.571 & 0.477 & 0.560 & 0.445 & 0.194 & 0.237 & 0.154 & 0.352 & 0.186 \\
Canada & 0.483 & 0.565 & 0.459 & 0.443 & 0.430 & 0.263 & 0.296 & 0.251 & 0.034 & 0.179 \\
France & 1.000 & 1.000 & 1.000 & 1.000 & 1.000 & 0.070 & 0.067 & 0.343 & 0.370 & 0.352 \\
Germany & 0.720 & 0.709 & 0.896 & 0.880 & 0.799 & -0.038 & -0.034 & 0.244 & 0.238 & 0.200 \\
India & 0.383 & 0.320 & 0.476 & 0.458 & 0.454 & 0.138 & 0.070 & 0.084 & 0.193 & 0.250 \\
Indonesia & 0.481 & 0.419 & 0.432 & 0.512 & 0.450 & 0.125 & 0.005 & -0.075 & 0.148 & 0.091 \\
Italy & 1.000 & 1.000 & 0.914 & 0.905 & 0.938 & 0.000 & 0.000 & 0.144 & 0.135 & 0.108 \\
Japan & 0.784 & 0.754 & 0.908 & 0.872 & 0.741 & -0.216 & -0.246 & -0.092 & -0.128 & -0.259 \\
Republic of Korea & 0.633 & 0.691 & 0.660 & 0.637 & 0.461 & -0.069 & 0.016 & -0.033 & -0.030 & -0.133 \\
Mexico & 0.674 & 0.664 & 0.739 & 0.660 & 0.555 & 0.117 & 0.095 & 0.314 & 0.080 & -0.059 \\
Russian & 0.509 & 0.510 & 0.418 & 0.386 & 0.327 & 0.042 & -0.119 & 0.025 & 0.265 & 0.088 \\
Saudi Arabia & 0.360 & 0.367 & 0.266 & 0.272 & 0.229 & -0.288 & -0.306 & -0.301 & -0.367 & -0.285 \\
South Africa & 0.450 & 0.501 & 0.481 & 0.186 & 0.186 & -0.013 & -0.080 & -0.052 & -0.017 & -0.023 \\
Turkey & 0.533 & 0.644 & 0.770 & 0.577 & 0.437 & -0.116 & 0.059 & 0.218 & 0.330 & 0.195 \\
UK & 1.000 & 1.000 & 1.000 & 1.000 & 1.000 & 0.000 & 0.000 & 0.000 & 0.000 & 0.000 \\
USA & 1.000 & 1.000 & 1.000 & 1.000 & 1.000 & 0.000 & 0.000 & 0.000 & 0.000 & 0.000 \\
China & 0.328 & 0.391 & 0.269 & 0.284 & 0.318 & 0.090 & 0.139 & -0.002 & -0.046 & 0.033 \\
\hline
\end{tabular}

Table 5. Significance test between TFEcE and TFEE in G20.

\begin{tabular}{ccccc}
\hline Indicators & Mann-Whitney $\mathbf{U}$ & Wilcoxon $\mathbf{W}$ & $\boldsymbol{Z}$-Value & $\boldsymbol{p}$-Value \\
\hline TFEcE vs. TFEE & $66,386.000$ & $146,186.000$ & -4.071 & $<0.001$ \\
\hline
\end{tabular}

\subsection{Factors of National TFEcE}

TFEcE of all the G20 countries every year lies always between zero and unity, thus it is a limited dependent variable. In order to distinguish the influential factors of national TFEcE, we follow the method of $\mathrm{Li}$ and $\mathrm{Hu}$ [23] and employ the truncated regression model based on the truncated characteristics of TFEcE data. Truncated regression models arise in many applications of statistics, cases where observation values in the outcome variable are below or above certain thresholds are systematically excluded from the sample.

Three factors are investigated in this paper. $R \mathcal{E} D$ represents the ratio of research and development expenditure to GDP. Tra is on behalf of the foreign dependence degree, which is the ratio of total exports and imports to GDP. Ind refers to the ratio of the secondary industry to GDP. All the data are obtained from the World Bank (World Development Indicators). Due to data limitations, the reduced sample data set from 2003-2013 is employed in this section. Saudi Arabia is excluded due to data missing in this section.

The truncated regression model is set as:

$$
\operatorname{TFEcE}_{o, t}=\beta_{0}+\beta_{1} R \& D_{o, t}+\beta_{2} \operatorname{Tr}_{0, t}+\beta_{3} \operatorname{Ind}_{0, t}+\varepsilon_{0, t}
$$

where TFEcE $E_{0, t}$ refers to the TFEcE in the oth country and the $t$ th year; $\beta_{0}$ is the constant term; $\beta_{1}, \beta_{2}$, and $\beta_{3}$, are the parameters of the independent variables, respectively; and $\varepsilon_{0, t}$ is the error term.

From the above descriptive statistics analysis and significance test in Section 4.2, we can find that there is significance difference in TFEcE between developed countries and developing countries, 
while an analysis on all the G20 countries of Formula (10) may cover it up. Therefore, Table 6 respectively analyzes the factors that influence TFEcE of the whole G20 countries, G20 developed countries and G20 developing countries. Overall, the result of all the G20 countries is basically consistent with that of G20 developed countries, while different from the one of G20 developing countries. Such results show the necessity of dividing G20 into developing countries and developed countries when analyzing the factors that influence TFEcE.

Table 6. Factors of national TFEcE scores in G20.

\begin{tabular}{|c|c|c|c|c|c|c|}
\hline \multirow{3}{*}{ Variables } & \multicolumn{2}{|c|}{ All the Countries } & \multicolumn{2}{|c|}{ Developed Countries } & \multicolumn{2}{|c|}{ Developing Countries } \\
\hline & \multirow{2}{*}{ Coefficient } & Significant Test & \multirow{2}{*}{ Coefficient } & \multirow{2}{*}{$\begin{array}{c}\text { Significant Test } \\
p \text {-Value }\end{array}$} & \multirow{2}{*}{ Coefficient } & \multirow{2}{*}{$\begin{array}{c}\text { Significant Test } \\
p \text {-Value }\end{array}$} \\
\hline & & $p$-Value & & & & \\
\hline \multicolumn{7}{|c|}{ Independent Variable } \\
\hline$R E D$ & 0.2507 & 0.000 & 0.5328 & 0.019 & -0.0950 & 0.001 \\
\hline Tra & -0.0010 & 0.594 & -0.0085 & 0.138 & 0.0045 & 0.000 \\
\hline Ind & -0.0214 & 0.000 & -0.0738 & 0.024 & -0.0003 & 0.894 \\
\hline Constant term & 0.8487 & 0.000 & 2.3007 & 0.002 & 0.1934 & 0.013 \\
\hline
\end{tabular}

First, to all the G20 countries, the coefficient of $R \mathcal{E} D$ is significantly positive which indicates that $R \mathcal{E} D$ has a significantly positive impact on TFEcE. It can be seen from Table 6 that $R \mathcal{E} D$ shows different statistical significance in the truncated regression model. The higher RED contributes to the higher TFEcE in developed countries, while it is opposite in developing countries. For the developed countries, the increase of $R \mathcal{E} D$ can boost technical progress, which may enhance the ecological resources usage efficiency and introduce much more ecologically-friendly technology to replace the traditional technology. For the developing countries, the improvement of labor efficiency and capital efficiency would be superior to that of ecological efficiency, because ecological resources are at a relatively low price or even free in developing countries. So, the $R \mathcal{E} D$ is more likely to be distributed to boost the technical progress related to labor or capital efficiency, rather than the improvement of the ecological efficiency. Therefore, we could not find that $R \mathcal{E D}$ promotes the increase of TFEcE in developing countries.

Second, to all the G20 countries, the coefficient of Ind is significantly negative which indicates that the ratio of the secondary industry to GDP has a significantly negative impact on TFEcE. It can be seen from Table 6 that the relationship between Ind and national TFEcE is different in developing countries and developed countries. Although Ind has led to a decrease in TFEcF in developed countries on average, it has not significantly done so to the developing countries. For developing countries, the ratio of the secondary industry to GDP not only stands for the industry structure but also represents the level of industrial development. Although the countries with a high ratio of secondary industry to GDP may develop a certain energy-intensive industry, the economic level of which are still above-average among the developing countries, which means compared with other developing countries with lower Ind, they tend to pay more attention to ecological problems. Due to the above-mentioned reasons, the relationship between Ind and national TFEcE is not significant in the developing countries.

Third, to all the G20 countries, the coefficient of Tra is not significant which indicates that there is not a significant relation between foreign dependence degree and TFEcE. It can be seen from Table 6 that Tra is beneficial to the higher national TFEcE in the developing countries, which is consistent with the internationalization effect. Based on imports and exports, the enterprises in developing countries could be affected by the strict ecological regulations of developed countries, and so their ecological protection awareness and technology level have improved. For the developed countries, we do not find internationalization effect is significantly beneficial to TFEcE. Developed countries are always the exporting countries of green technology and eco-friendly concepts in international trade. Thus, from the perspective of TFEcE, international trade may be not significantly beneficial to developed countries. 


\section{Conclusions}

This paper studies the ecological efficiency of G20 using the index of TFEcE which is constructed on the viewpoint of total-factor framework by taking the ratio of target ecology input from an SBM model to the actual ecology input. The TFEcE index not only considers EF as the comprehensive ecological inputs, but also takes capital and labor into account as multi-inputs to produce GDP. The main conclusions are as follows:

For the G20 countries, the total EF of G20 maintains a stable growth trend from 1999 to 2013, increases from 962.45910 million ha in 1999 to 1203.47510 million ha in 2013, and achieves a growth of about $25 \%$. Fossil energy land contributes most to the total EF among the six components, accounting for $33.77 \%$. The contribution of forest and pasture land are $25.38 \%$ and $23.42 \%$, respectively.

In general, the average level of TFEcE of G20 from 1999 to 2013 is at a low level of about 0.54, which means there is a large space for improvement in the TFEcE of G20 countries. This indicates that the improvement of ecological efficiency is an effective way to maintain economic growth, and meanwhile, to relieve ecology pressures. Furthermore, TFEcE of G20 is very imbalanced. There is a big gap between developed countries and developing countries. The average level of developed countries is 0.727, of which the USA, UK, and Japan always have optimal efficiency from 1999 to 2013, while the average value of developing countries is only 0.376 , among which Argentina is at the lowest level of 0.21 .

Without considering other ecological impacts, TFEE in Hu and Wang [3] may overestimate the countries' performance. We find that there are significant differences between TFEE and TFEcE. Some countries—such as Japan, Republic of Korea, and Saudi Arabia—obtain higher score in TFEcE than that in TFEE due to a good performance in biological footprint. Some countries such as China, gain lower score in TFEcE than that in TFEE due to too much biological footprint consumption.

For the developing countries and developed countries, the analysis of factors that affect national TFEcE shows different statistical significance in the truncated regression model. The higher ratio of $R \mathcal{E} D$ expenditure to GDP contributes to a higher TFEcE in the developed countries, while a lower TFEcE in developing countries. Although the ratio of the secondary industry to GDP have negative effects on the developed countries' TFEcE, it has not significantly done so to the developing countries. The higher foreign dependence degree is beneficial to the higher national TFEcE in the developing countries.

Our study presents several policy implications.

First, as global warming, deforestation, land erosion, and loss of biodiversity have become global issues nowadays, governments should not only focus on the consumption and utilization of energy efficiency, but analyze the use efficiency of ecological resources from the view of ecological footprint. TFEcE indicator that integrates labor, capital, and ecological inputs could provide more comprehensive evaluation criteria for the policy-making of sustainable development.

Second, although there exists significant difference between developed countries and developing countries, not all the developed countries have a high TFEcE. Australia and Canada, as developed countries, have higher total EF values because of a larger pasture and forest land footprint. For these two countries, we recommend they pay more attention to improving the use efficiency of pasture and forest land footprint to cut down the occupation of the total EF and thus increasing their TFEcE.

Third, developed countries and developing countries should take different measures to promote TFEcE. Since developing countries have to realize ecological protection when pursuing economic growth, they face more severe challenges. We suggest that developing countries, on the one hand, guide $R \& D$ expenditure and its distribution to improve ecological efficiency, thus promoting domestic green technology innovation, on the other hand, developing countries should actively obtain internationalization effects, promoting TFEcE by acquiring green spillovers through international trade.

Acknowledgments: This work is supported by the National Natural Science Foundation of China (71303042, 71503039), National Social Science Foundation of China (12\&ZD207), and the Key Project of Philosophy and Social Science Research in Colleges and Universities of Jiangsu Province (2015ZDIXM004). 
Author Contributions: Shujing Yue and Yang Yang had the original idea for the study. Yuting Zhu was responsible for data collecting. Shujing Yue and Jun Shao carried out the analyses.

Conflicts of Interest: The authors declare no conflict of interest.

\section{References}

1. World Business Council for Sustainable Development. Eco-Efficiency: Creating More with Less. 2000. Available online: http://www.wbcsd.org/web/publications/eco_efficiency_creating_more_value.pdf (accessed on 1 August 2016).

2. Patterson, M.G. What is energy efficiency? Concepts, indicators and methodological issues. Energy Policy 1996, 24, 377-390. [CrossRef]

3. Hu, J.L.; Wang, S.C. Total-factor energy efficiency of regions in China. Energy Policy 2006, 34, 3206-3217. [CrossRef]

4. Freeman, A.M.; Haveman, R.H.; Kneese, A.V. Economics of Environmental Policy; John Wiley \& Sons: New York, NY, USA, 1973.

5. Schaltegger, S.; Sturm, A. Öologische Rationalität. Die Unternehmung 1990, 4, 117-131. (In German)

6. Schmidheiny, S. Changing Course: A Global Business Perspective on Development and the Environment; MIT Press: Cambridge, UK, 1992.

7. Zhao, M.Y.; Cheng, C.T.; Chau, K.W.; Li, G. Multiple criteria data envelopment analysis for full ranking units associated to environment impact assessment. Int. J. Environ. Pollut. 2006, 28, 448-464. [CrossRef]

8. Zhang, B.; Bi, J.; Fan, Z.; Yuan, Z.; Ge, J. Eco-efficiency analysis of industrial system in China: A data envelopment analysis approach. Ecol. Econ. 2008, 68, 306-316. [CrossRef]

9. Yu, Y.D.; Chen, D.J.; Zhu, B.; Hu, S.Y. Eco-efficiency trends in China, 1978-2020: Decoupling environmental pressure from economic growth. Ecol. Indic. 2013, 24, 177-184. [CrossRef]

10. Wang, W.; Jiang, D.; Chen, D.J.; Chen, Z.B.; Zhou, W.J.; Zhu, B. A Material Flow Analysis (MFA)-based potential analysis of eco-efficiency indicators of China's cement and cement-based materials industry. J. Clean. Prod. 2015, 112, 787-796. [CrossRef]

11. Rees, W.E. Ecological footprint and appropriated carrying capacity: What urban economics leaves out. Environ. Urban. 1992, 4, 121-130. [CrossRef]

12. Wackernagel, M.; Rees, W.E. Our Ecological Footprint: Reducing Human Impact on the Earth; New Society Publishers: Gabriola Island, BC, Canada, 1996.

13. Moffatt, L. Ecological footprints and sustainable development. Ecol. Econ. 2000, 32, 359-362.

14. Kratena, K. "Ecological value added" in an integrated ecosystem model-An indicator for sustainability. Ecol. Econ. 2004, 48, 189-200. [CrossRef]

15. Chen, D.J.; Cheng, G.D.; Xu, Z.M.; Zhang, Z.Q. Ecological footprint of the Chinese population, environment and development. Environ. Conserv. 2004, 31, 63-68.

16. Fu, W.; Turner, J.C.; Zhao, J.Q.; Du, G.Z. Ecological footprint (EF): An expanded role in calculating resource productivity (RP) using China and the G20 member countries as examples. Energy Policy 2015, 48, 464-471. [CrossRef]

17. Miao, C.L.; Sun, L.Y.; Yang, L. The studies of ecological environmental quality assessment in Anhui province based on ecological footprint. Ecol. Indic. 2016, 60, 879-883. [CrossRef]

18. Hu, J.L.; Wang, S.C.; Yeh, F.Y. Total-factor water efficiency of regions in China. Resour. Policy 2006, 31, $217-230$. [CrossRef]

19. Hu, J.L.; Kao, C.H. Efficient energy-saving targets for APEC economies. Energy Policy 2007, 35, 373-382. [CrossRef]

20. Honma, S.; Hu, J.L. Total-factor energy efficiency of regions in Japan. Energy Policy 2008, 36, 821-833. [CrossRef]

21. Zhang, X.P.; Cheng, X.M.; Yuan, J.H.; Gao, X.J. Total-factor energy efficiency in developing countries. Energy Policy 2011, 39, 644-650. [CrossRef]

22. Chang, T.P.; Hu, J.L. Total-factor energy productivity growth, technical progress, and efficiency change: An empirical study of China. Appl. Energ. 2010, 87, 3262-3270. [CrossRef]

23. Li, L.B.; Hu, J.L. Ecological total-factor energy efficiency of regions in China. Energy Policy 2012, 46, $216-224$. [CrossRef] 
24. Zhang, N.; Kong, F.B.; Yu, Y.N. Measuring ecological total-factor energy efficiency incorporating regional heterogeneities in China. Ecol. Indic. 2015, 51, 165-172. [CrossRef]

25. World Wildlife Fund. Living Planet Report. 2006. Available online: http://wwf.panda.org/about_ our_earth/all_publications/living_planet_report/living_planet_report_timeline/lp_2006/ (accessed on 8 August 2016).

26. Wackernagel, M.; Onisto, L.; Bello, P.; Linares, A.C.; Falfan, I.S.L.; Garcia, J.M.; Guerrero, A.I.S.; Guerrero, M.G.S. National natural capital accounting with the ecological footprint concept. Ecol. Econ. 1999, 29, 375-390. [CrossRef]

27. Charnes, A.; Cooper, W.W.; Rhodes, E. Measuring efficiency of decision making units. Eur. J. Oper. Res. 1978, 2, 429-444. [CrossRef]

28. Banker, R.D.; Charnes, A.; Cooper, W.W. Some models for estimating technical and scale efficiencies in data envelopment analysis. Manag. Sci. 1984, 30, 1078-1092. [CrossRef]

29. Tone, K. A slacks-based measure of efficiency in data envelopment analysis. Eur. J. Oper. Res. 2001, 130, 498-509. [CrossRef]

30. Fukuyama, H.; Weber, W.L. A directional slacks-based measure of technical efficiency. Socio-Econ. Plan. Sci. 2009, 43, 274-287. [CrossRef]

31. Young, A. Gold into base metals: Productivity growth in the People's Republic of China during the reform period. J. Political Econ. 2003, 6, 1220-1261. [CrossRef]

32. Nehru, V.; Dhareshwar, A. A new database on physical capital stock: Sources, methodology and results. Econ. Anal. Rev. 1993, 8, 37-59.

(C) 2016 by the authors; licensee MDPI, Basel, Switzerland. This article is an open access article distributed under the terms and conditions of the Creative Commons Attribution (CC-BY) license (http://creativecommons.org/licenses/by/4.0/). 